\title{
An Innovative Approach to Educating Medical Students About Personal Finance
}

\author{
Kabir Grewal ${ }^{1}$, Michael J. Sweeney ${ }^{2}$ \\ 1. Department of Clinical Sciences, Florida State University College of Medicine, Tallahassee, USA 2. Department of \\ Surgery, Florida State University College of Medicine, Tallahassee, USA
}

Corresponding author: Michael J. Sweeney, michael.sweeney@med.fsu.edu

\section{Abstract \\ Background}

The lack of financial literacy among medical students and physicians is a well-documented problem that is yet to be sufficiently addressed. The full immersion of physicians into their scientific education and medical training makes it challenging to also comprehensively learn about personal finance. With the vast debt that most medical students undergo, it is crucial to focus on this issue.

\section{Methodology}

To address this challenge, faculty at The Florida State University College of Medicine (FSU COM) have created a fully online personal finance elective course for fourth-year medical students. This course, titled Personal Finance for the New Physician, focuses on critical fiscal topics that are directly relevant to future doctors. The elective is delivered remotely through the utilization of online discussion boards, weekly video conferences, and recorded lectures by financial experts. This innovative distribution model ensures that busy students can educate themselves regardless of time or location.

\section{Results}

Initially offered in January of 2019, Personal Finance for the New Physician quickly became the most chosen elective at FSU COM. To determine the course's efficacy, students completed a questionnaire at both the start and end of the elective. The results show substantial improvements in fiscal knowledge and confidence in managing personal finances. The average financial competence score of those who completed the course increased from a $2.25 / 5$ to a $4.45 / 5$. Feedback from students so far has been exceedingly positive.

\section{Conclusions}

Personal Finance for the New Physician has been effective at addressing the lack of financial knowledge that is prevalent among medical students. Additionally, the unique online nature of this course would allow for realistic expansion to other medical programs. Course directors will continue to receive feedback from

Received 03/11/2021 Review began 05/20/2021 Review ended 06/06/2021 Published 06/10/2021

\section{() Copyright 2021}

Grewal et al. This is an open access article distributed under the terms of the Creative Commons Attribution License CC-BY 4.0., which permits unrestricted use, distribution, and reproduction in any medium, provided the original author and source are credited. students, financial experts, and physicians to modify and improve the elective.

Categories: Medical Education, Other

Keywords: personal finance, medical school debt, physician loans

\section{Introduction}

During medical school, students spend countless hours learning about the scientific intricacies of the human body. Through clinical training, students learn how to properly care for patients and become the best physicians possible. This process of total immersion into the art and science of medicine often prevents students from focusing on other topics that are important to their career and life. One such critical area is personal finance. A lack of financial knowledge and planning among physicians can lead to an uncertain future burdened by poor decision-making. This dearth of knowledge often first becomes an issue during college and medical school when many students do not understand the full consequences of student debt. As a result, we believe this lack of knowledge should be adequately addressed in medical school, specifically during the fourth year. This is the time period during which curriculum time is available and student interest in personal finance increases in anticipation of employment. However, the fourth year is also when students tend to travel for residency interviews and engage in external clinical rotations. These factors demand an innovative approach for the delivery of education content that offers both temporal and geographical flexibility. This inspired us to create a personal finance education elective consisting of recorded lectures by content experts and weekly live video discussions.

Currently, the average total education debt faced by a medical school graduate surpasses $\$ 251,600$, and over the standard course of four years of premedical studies, four years of medical school, and three to seven years spent in residency training, doctors are often forced to allow significant expansion of this debt load 
prior to implementing a repayment strategy [1]. The current trend of increasing medical sub-specialization only exacerbates this challenge for new physicians [2]. The ever-expanding regulatory environment and decreasing reimbursements are but some of the additional reasons financial education will become more important than ever for doctors [2]. As a result, it seems essential for physicians, including those in training, to be adequately prepared to manage their debt effectively within the context of their overall personal finances.

Major concerns moving forward include the detrimental emotional and psychological impacts that a lack of financial knowledge can have on physicians, especially those early in their professional careers. The transition from the protected medical school environment, to the well-structured world of residency, to independent or employed practice can be confusing and intimidating. These transitional difficulties are often exacerbated by feelings of inadequate preparation, unprecedented responsibilities, and the struggle to adjust to one's role in a hierarchical healthcare system. A recent survey regarding this topic found that as many as $82 \%$ of medical interns reported symptoms of burnout [3]. A less anticipated result showed that, of the challenges frequently faced by interns, financial worries ranked the highest, with nearly $72 \%$ of interns reporting high or very high stress from this concern [3]. Many new physicians use words such as "frightening" and "terrifying" to describe purchasing insurance or dealing with their student debt [4]. A separate survey found that even among program directors, the presence of considerable financial stress was significantly correlated with higher levels of emotional exhaustion and depersonalization [5]. We believe that providing earlier financial training can help alleviate these effects, and that reducing external stress on physicians may improve overall wellness, professional satisfaction, as well as patient interactions and outcomes.

The typical premedical student is required to take dozens of rigorous science courses while gaining clinical exposure as well as studying for the Medical College Admission Test. Once in medical school, these students must then fully immerse themselves into their medical studies and clinical rotations. Due to a lack of time, interest, or awareness, many of these students fail to recognize personal finance as important to their future until they near the end of their medical education. This can be seen at the Florida State University College of Medicine (FSU COM), where, historically, less than $5 \%$ of medical students have significant formal education in personal finance, business principles, or any related disciplines. A broader survey completed by over 1,000 medical students from various medical schools found that only $56.6 \%$ of M4s received personal finance counseling or education during medical school [6]. Respondents to this same survey also scored an average of only $47.7 \%$ correct on a basic financial literacy quiz [6]. These data results provide evidence of the need to improve the financial education of medical students.

\section{Materials And Methods}

\section{Addressing the issue}

Over the last few years, multiple initiatives have been made across the country to alleviate this problem. For example, the number of joint MD/MBA programs in the United States has risen from six to nearly seventy within the last 25 years [7]. Although this option delivers general business knowledge and skills, these programs do not focus on personal financial management and are not a fully viable solution. Most medical students are unlikely to spend one to two years and undergo additional debt to pursue yet another degree. A preferable solution should instead require less interruption of basic medical education and be more readily available to a wider population of students while not adding debt [8].

As a result, several institutions have begun experimenting with different ways to educate students about finance within the confines of the traditional four-year medical school curriculum. In 2013, students at the Michigan State University College of Human Medicine created an elective course to learn about the basics of personal finance, student debt handling, and business management [9]. Nearly $85 \%$ of students felt that they benefited from taking the elective, and 30\% believed that the Medical Business and Finance elective should become mandatory in their medical school curriculum [9]. A similar initiative was made at the University of Arkansas for Medical Sciences, where a 10-week Business of Medicine elective course has been held annually. Data reported from 2015-2018 show that the percentage of fourth-year medical students who chose to enroll in this course increased from $43 \%$ to $77 \%$ [10]. Of those who took the course, $98.9 \%$ said that the knowledge gained in this course would be helpful in the future [10]. These sorts of positive results have encouraged us at the FSU COM to create our own personal finance curriculum and to develop an innovative delivery model to ensure its availability to all our medical students.

\section{The FSU COM approach}

The FSU COM utilizes a distributive model of clinical education and training in which students spend their final two years of medical school at one of six regional campuses and three additional sites across the state of Florida. While this model has proven effective at preparing graduates for residency and beyond, it posed certain challenges to designing and delivering a personal finance elective to fourth-year medical students. Most notably, we needed to create a course that was easily accessible across multiple locations. Through the input and contributions of various faculty members at the FSU College of Business, we developed a curriculum that allowed for the combination of recorded video lectures, supplementary readings on relevant topics, and weekly live video conferences between students and course directors. The implementation of 


\section{Cureus}

video technology and recordings enabled students to access the learning modules at any time from anywhere. This led to near-universal accessibility for participants even while juggling residency interviews, clinical rotations, and unanticipated events such as the coronavirus disease 2019 lockdown.

\section{Personal Finance for the New Physician}

The course, titled Personal Finance for the New Physician, is delivered over four weeks and encompasses nine different topics that are directly applicable to future physicians (see Table 1). These relevant subjects include debt management, risk insurance, retirement planning, and contract negotiations. Recorded video lectures on each topic are created by FSU College of Business professors and additional content experts with graduate-level expertise in their fields. To protect the integrity of the course, we at FSU deemed it crucial that the contributing faculty had no financial conflicts of interest associated with any of the material they presented. This ensures the information taught to medical students is as unbiased as possible. Upon watching the lectures and reading the required materials, participants are required to participate in the online discussion sessions. At the conclusion of the course, students are required to submit a reflection project detailing their own personal financial strategy moving forward.

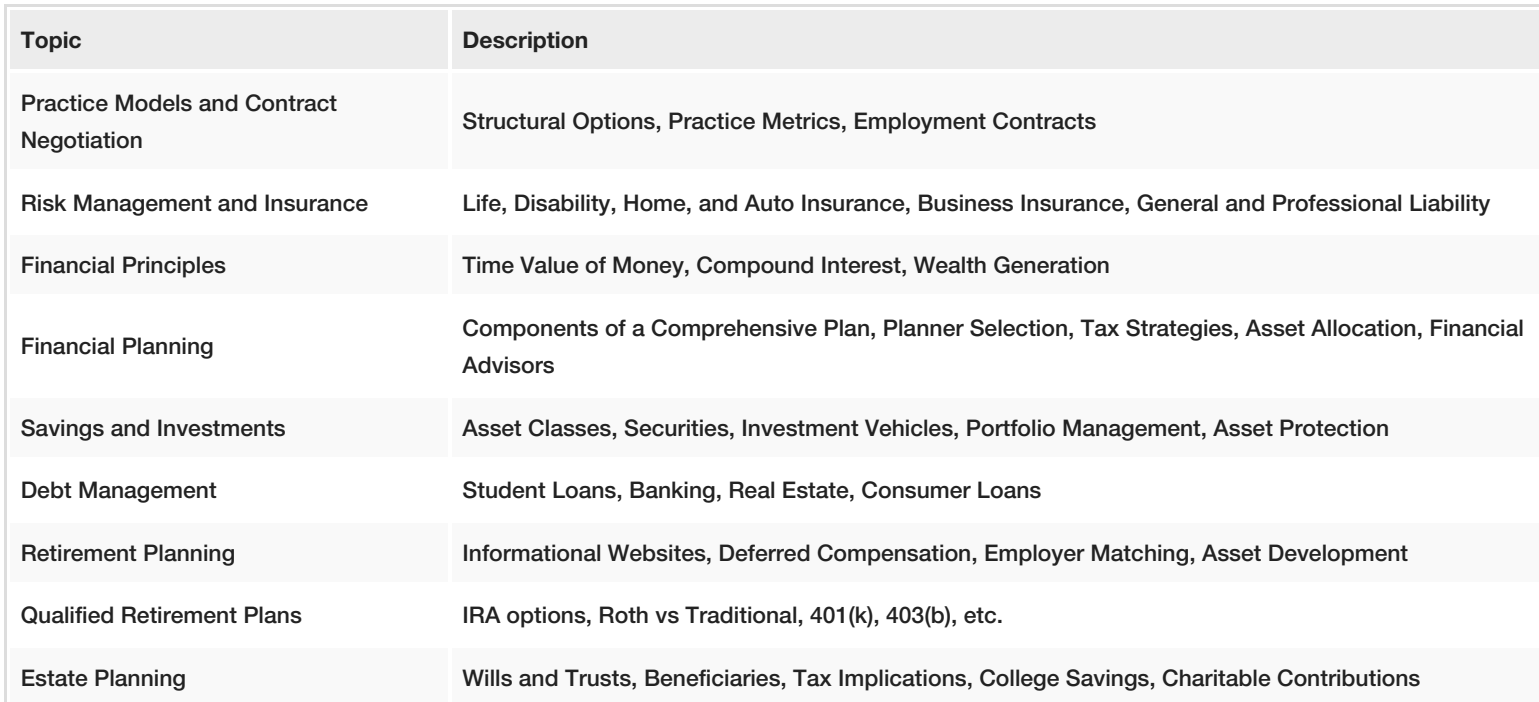

TABLE 1: Course syllabus outline for Personal Finance for the New Physician.

\section{Results}

A short questionnaire was given to students both prior to and after completing the elective. This 10question survey asked students to self-assess their knowledge about various fiscal topics. Blinded survey responses were anonymous, participation was voluntary, and no privileged, confidential, or personal identifying information was included. The survey design provided an Institution Review Board exemption by the research committee at FSU.

Of the 201 students who have taken the course thus far, 160 students answered the initial questionnaire and 123 completed the follow-up survey upon completion of the course. After assigning a numerical value to each answer, we calculated a mean competence score for each topic. The results indicated a significant increase across the board in student confidence in fiscal knowledge and in facing personal financial issues. Substantial increases were observed in responses to survey questions on each of the covered topics, as shown in Table 2, with the overall self-assessed mean competence score rising from 2.25/5 to 4.45/5. 


\section{Cureus}

\begin{tabular}{|c|c|c|}
\hline \multirow{2}{*}{ Survey questions } & \multicolumn{2}{|c|}{$\begin{array}{l}\text { Average competence } \\
\text { score (1-5) }\end{array}$} \\
\hline & $\begin{array}{l}\text { Pre-course } \\
(n=160)\end{array}$ & $\begin{array}{l}\text { Post-course } \\
(n=123)\end{array}$ \\
\hline Question 1: I feel confident about my personal finance knowledge and skills & 2.28 & 4.29 \\
\hline Question 2: I am comfortable managing my budget and finances & 2.98 & 4.46 \\
\hline $\begin{array}{l}\text { Question 3: I am aware of various structural options for medical practice along with the general advantages and } \\
\text { disadvantages of each }\end{array}$ & 2.16 & 4.37 \\
\hline $\begin{array}{l}\text { Question 4: I am able to assess my current and future need for risk management and evaluate various insurance } \\
\text { options from a personal and professional perspective }\end{array}$ & 1.89 & 4.44 \\
\hline Question 5: I understand basic financial principles such as time value of money and wealth accumulation & 2.93 & 4.62 \\
\hline Question 6: I am familiar with the basics of tax planning, asset allocation, and financial advisor selection & 1.95 & 4.41 \\
\hline $\begin{array}{l}\text { Question 7: I can distinguish between savings and investments and can describe the basic characteristics of } \\
\text { various asset classes }\end{array}$ & 2.52 & 4.57 \\
\hline $\begin{array}{l}\text { Question 8: I appreciate the importance of debt management in personal finance and can build a strategy to } \\
\text { address the issue }\end{array}$ & 3.08 & 4.66 \\
\hline $\begin{array}{l}\text { Question 9: I can discuss the importance of long-term planning for future financial obligations, including } \\
\text { retirement, college education costs, charitable giving, and estate planning }\end{array}$ & 2.86 & 4.64 \\
\hline $\begin{array}{l}\text { Question 10: I am aware of various options for retirement planning and can discuss the basics and tax implications } \\
\text { of each }\end{array}$ & 2.01 & 4.38 \\
\hline
\end{tabular}

\section{TABLE 2: Pre-/Post-course student survey results (2019-2020).}

Students answered "Strongly Disagree" (1), "Disagree" (2), "Neutral” (3), "Agree" (4), or "Strongly Agree” (5) to each question. The corresponding numerical values were used in calculating the average competence scores. Out of the 160 students who filled out the pre-course survey, 123 also filled out the post-course survey.

\section{Discussion}

This course was first offered in January of 2019 and quickly became the most chosen elective among fourthyear medical students at FSU COM. This highlights the demand and desire among medical students to improve their personal finance knowledge. The preliminary results from those who have taken Personal Finance for the New Physician are encouraging and showcase the efficacy of the elective. The survey responses also help exhibit the effectiveness of the course. In their Final Project submissions, most students expressed gratitude for the opportunity to participate in this elective. Satisfaction with the scope, structure, and pedagogy of the course has also been extremely high. The fully virtual nature of this course could soon help address the widespread deficiency of personal finance knowledge among medical students in this country.

\section{Conclusions}

To educate our fourth-year medical students about personal finance, the FSU COM has designed and implemented an innovative course to provide accessibility to students regardless of their educational site or individual schedules. Initial results from our elective course indicate that it has been very successful in achieving the objective of better preparing our graduates to manage their personal finances. Those who have completed the course report dramatic increases in their financial knowledge as well as enhanced confidence in their ability to effectively manage future fiscal challenges. As a result, we believe that Personal Finance for the New Physician has and will continue to help ensure that our graduates receive a truly comprehensive education prior to transitioning to residency and on to their professional careers. The course's online design provides distributive access, flexible content engagement, and offers scalability which can be expanded or replicated in response to increased demand. Therefore, this sort of course structure could yield itself to future widespread adoption by medical students across the country.

Moving forward, we will continue to gather feedback from students to best improve and enhance the course's learning modules and overall structure. We will also acknowledge suggestions from students about which fiscal topics we should further emphasize. Furthermore, we will pursue suggestions and critiques from both practicing physicians and financial experts regarding how to best advance the elective. 


\section{Additional Information}

Disclosures

Human subjects: Consent was obtained or waived by all participants in this study. FSU IRB issued approval STUDY00002278. Blinded survey responses were anonymous, participation voluntary, and no privileged, confidential, or personal identifying information was included. The survey design provided an IRB exemption by the research committee at FSU. Animal subjects: All authors have confirmed that this study did not involve animal subjects or tissue. Conflicts of interest: In compliance with the ICMJE uniform disclosure form, all authors declare the following: Payment/services info: All authors have declared that no financial support was received from any organization for the submitted work. Financial relationships: All authors have declared that they have no financial relationships at present or within the previous three years with any organizations that might have an interest in the submitted work. Other relationships: All authors have declared that there are no other relationships or activities that could appear to have influenced the submitted work.

\section{Acknowledgements}

The authors would like to thank faculty at both the Florida State University College of Business as well as College of Medicine for their contributions to the development of this course.

\section{References}

1. Average student loan debt for medical school. (2020). Accessed: April 20, 2020: https://www.credible.com/blog/statistics/average-medical-school-debt/.

2. Bar-Or Y: Empowering physicians with financial literacy . J Med Pract Manage. 2015, 31:46-9.

3. Hannan E, Breslin N, Doherty E, McGreal M, Moneley D, Offiah G: Burnout and stress amongst interns in Irish hospitals: contributing factors and potential solutions. Ir J Med Sci. 2018, 187:301-7. 10.1007/s11845017-1688-7

4. Young doctors go to business school for a day . (2015). Accessed: April 19, 2020: https://buffalonews.com/business/local/young-doctors-go-to-business-school-for-a-day/article_5b656505a774-5eda-a664-...

5. Porter M, Hagan H, Klassen R, Yang Y, Seehusen DA, Carek PJ: Burnout and resiliency among family medicine program directors. Fam Med. 2018, 50:106-12. 10.22454/FamMed.2018.836595

6. Jayakumar KL, Larkin DJ, Ginzberg S, Patel M: Personal financial literacy among U.S. medical students . MedEdPublish. 2017, 6:35. 10.15694/mep.2017.000035

7. The rise of the M.D./M.B.A. degree . (2014). Accessed: February 15, 2020: https://www.theatlantic.com/education/archive/2014/09/the-rise-of-the-mdmba-degree/380683/.

8. Steps to incorporate business knowledge into the medical school curriculum . (2014). Accessed: March 10, 2020: https://vascularspecialistonline.com/steps-to-incorporate-business-knowledge-into-the-medicalschool-curriculum/.

9. Meleca JB, Tecos M, Wenzlick AL, Henry R, Brewer PA: A medical student initiated elective course in business and finance: a needs analysis and pilot. Med Stud Res J. 2014, 4:18-23.

10. Mizell JS, Thrush CR, Steelman S: The business of medicine: a course to address the deficit in financial knowledge of fourth-year medical students. J Med Pract Manag. 2019, 34:344. 